\title{
Contribución de las cooperativas agrarias al desarrollo territorial en Uruguay
}

Contribution of agricultural cooperatives to territorial development in Uruguay

\section{Contribuição de cooperativas agrícolas desenvolvimento territorial em Uruguay}

\section{Adrián Rodríguez Miranda ${ }^{1}$ Juan Pablo Martí ${ }^{2}$ Mariana Rodríguez Vivas ${ }^{3}$}

Recibido: 3 de marzo de 2020 Aprobado: 25 de noviembre de 2020

Publicado: 15 de enero de 2021

Cómo citar este artículo:

Rodríguez Miranda, A., Martí, J.P. y Rodríguez Vivas, M. (2021). Contribución de las cooperativas agrarias al desarrollo territorial en Uruguay. Cooperativismo \&

Desarrollo, 29(119), 1-31. doi: https://doi.org/10.16925/2382-4220.2021.01.02

Artículo de investigación. https://doi.org/10.16925/2382-4220.2021.01.02

1 Instituto de Economía, Facultad de Ciencias Económicas y Administración, Universidad de la República, Uruguay.

Correo electrónico: adrianrm@iecon.ccee.edu.uy

ORCID: http://orcid.org/0000-0002-0096-1624

1 Programa de Historia Económica y Social, Facultad de Ciencias Sociales, Universidad de la República, Uruguay.

Correo electrónico: juanpablo.marti@cienciassociales.edu.uy

ORCID: http://orcid.org/0000-0002-4162-1773

1 Instituto de Economía, Facultad de Ciencias Económicas y Administración, Universidad de la República, Uruguay.

Correo electrónico: mrodriguez@iecon.ccee.edu.uy ORCID: http://orcid.org/0000-0001-5992-0846 


\section{Resumen}

Este artículo tiene como objetivo explorar la relación entre cooperativismo agrario y desarrollo territorial en Uruguay. Se presenta un marco conceptual que argumenta los importantes puntos de encuentro que existen entre ambos enfoques, utilizando como nexo la noción de desarrollo endógeno, asociada con la construcción de capacidades locales. La metodología consiste en un análisis descriptivo y exploratorio con perspectiva histórica. Las fuentes de información son de tipo bibliográfica y documental, información secundaria disponible y entrevistas a informantes calificados. Se busca describir y comprender cómo el cooperativismo agrario ha contribuido al desarrollo territorial rural en Uruguay. Primero se analiza la historia y evolución del movimiento cooperativo uruguayo, para luego profundizar en el cooperativismo agrario, sus orígenes, casos más representativos y evolución. Los resultados muestran una contribución positiva de las cooperativas agrarias al desarrollo territorial, en buena medida apuntaladas por la política pública. En ese sentido, las cooperativas facilitan la vinculación competitiva del territorio con los mercados internacionales, pero protegiendo a los sistemas productivos locales de ser absorbidos y diluidos dentro del esquema del capital transnacional; a su vez, favorecen capacidades endógenas de innovación y la construcción de capital social local y de redes que son la base de las estrategias locales de desarrollo.

Palabras clave: cooperativas agrarias, cooperativismo, desarrollo territorial rural, desarrollo territorial, desarrollo local

J54 Cooperativas de productores

P13 Empresas cooperativas

P25 Economía rural y regional

\section{Abstract}

The aim of the article is to analyze the relationship between agricultural cooperativism and territorial development in Uruguay. First, the theoretical bases of the territorial development approach are presented, highlighting the coincidences with cooperativism. From this, the category of endogenous development is proposed as the main link between the two approaches. The methodology consists of a descriptive and exploratory analysis, with a historical focus, based on a bibliographic and documentary review, secondary information and interviews with key actors. To obtain the results, the history and evolution of cooperativism in Uruguay is analyzed, and then it focuses on agricultural cooperativism, its origins, its most representative cases and its evolution. The results show a positive contribution of agricultural cooperatives to territorial development, supported on an important role of public policies. Cooperatives promotes the competitiveness of the territory in international markets but protects the local productive systems of small producers from the logic of concentration and exclusion of transnational capital. In turn, cooperatives favor endogenous capacities for innovation and the construction of local social capital and networks that are the basis of local development strategies.

Keywords: agricultural cooperatives, cooperativism, rural territorial development territorial development, local development, Uruguay.

\section{Resumo}

O objetivo do artigo é analisar a relação entre cooperativismo agropecuário e desenvolvimento territorial no Uruguai. Primeiramente, são apresentadas as bases teóricas da abordagem do desenvolvimento territorial, destacando as coincidências com o cooperativismo. A partir disso, a categoria de desenvolvimento endógeno é proposta como o principal elo entre as duas abordagens. A metodologia consiste em uma análise descritiva e exploratória, com enfoque histórico, baseada em revisão bibliográfica e documental, informações secundárias e entrevistas com atores-chave. Para obter os resultados, analisa-se a história e evolução do cooperativismo 
no Uruguai e, a seguir, enfoca o cooperativismo agropecuário, suas origens, seus casos mais representativos e sua evolução. Os resultados mostram uma contribuição positiva das cooperativas agropecuárias para o desenvolvimento territorial, amparadas em um importante papel das políticas públicas. 0 cooperativismo promove a competitividade do território nos mercados internacionais, mas protege os sistemas produtivos locais dos pequenos produtores da lógica da concentração e exclusão do capital transnacional. Por sua vez, as cooperativas favorecem as capacidades endógenas de inovação e construção de capital social local e redes que são a base das estratégias de desenvolvimento local.

Palavras-chave: cooperativas agrícolas, cooperativismo, desenvolvimento territorial rural, desenvolvimento territorial, local desenvolvimento, Uruguay.

\section{Introducción}

Este artículo tiene como objetivo analizar la relación entre el cooperativismo agrario y el desarrollo territorial en Uruguay. Una motivación, de carácter más general, se refiere al interés de poner en diálogo al cooperativismo con el desarrollo territorial, dos corrientes de pensamiento con una fuerte base en la praxis orientada por principios y valores. La confluencia de estos dos enfoques representa una oportunidad para avanzar en la construcción de estrategias propias de desarrollo, alternativas al modelo productivo predominante del agronegocio global.

En efecto, si bien las políticas de desarrollo territorial en América Latina han ido ganando un espacio cada vez más relevante entre organismos públicos internacionales de referencia (CEPAL, 2017, 2019), la articulación y el diálogo entre este enfoque y el cooperativismo es todavía insuficiente. Este artículo busca contribuir con los aportes que han ido emergiendo, principalmente desde la academia, para dejar en evidencia la relación positiva y sinérgica entre el cooperativismo (en particular el agrario) y los procesos de desarrollo territorial. En esa línea, este trabajo describe esas relaciones para el caso uruguayo, con el objetivo de comprender mejor el fenómeno y extraer algunas reflexiones más generales acerca de la importancia de fortalecer el diálogo entre estos dos enfoques.

Desde la perspectiva del desarrollo económico territorial, es importante resaltar aquellas formas de organizar la producción que generan mayor apropiación local de la riqueza. El objetivo es promover una mejor distribución de la riqueza que se genere directamente, a partir de cómo se organiza el propio proceso productivo, y sin que esto dependa solamente de que exista un proceso de redistribución ex post (por ejemplo, vía impuestos). Los territorios que logran este tipo de proceso se pueden identificar con la noción de desarrollo endógeno, en el sentido económico, como lo plantea Boisier (1993). Bajo este modelo de producción, distribución y comercialización, los actores locales son capaces de tomar control sobre la generación del excedente económico y, por lo tanto, poseen capacidad de apropiación y decisión sobre su uso y reinversión. 
En ese orden de ideas, este artículo busca ofrecer argumentos que pueden alimentar el debate sobre la importancia de este tema para América Latina, donde la producción agrícola representa gran parte del origen de la riqueza. El acento no se debería poner solamente en el crecimiento económico sino en cómo las sociedades locales se organizan para producir. Al respecto, las políticas aplicadas en la primera década del siglo XXI, durante el boom de precios internacionales de las materias primas, promoviendo la redistribución de ingresos vía impuestos y transferencias, fueron, sin lugar a duda, muy exitosas para bajar la pobreza y ayudar a las poblaciones vulnerables. Sin embargo, el modelo productivo no cambió significativamente. No hubo un proceso de mayor endogeneidad en la toma de decisiones respecto al proceso productivo y la apropiación del excedente económico.

En el contexto del boom de precios agrícolas se podían obtener grandes volúmenes de producción y exportación con un modelo de base extractiva y monoproductiva, liderado por empresas transnacionales que aportaban la última tecnología disponible. Luego, con una adecuada correlación de fuerzas y una economía en crecimiento, fue posible el desarrollo de una política redistributiva ex post. Pero ¿qué pasa cuando ese proceso liderado desde fuera (exógeno) termina? ¿Qué alternativas tienen los territorios para mantener el nivel de bienestar alcanzado?` ¿Qué modelo alternativo y endógeno se puede adoptar? ¿Con qué actores locales se puede impulsar ese proceso?

Aportar a la construcción conceptual y práctica de puentes entre el cooperativismo agrario y las políticas de desarrollo territorial puede contribuir a responder algunas de estas preguntas. Esto adquiere mayor relevancia cuando llega al final el ciclo de crecimiento dirigido por el gran capital del agronegocio y queda al descubierto un trasfondo de desigualdades estructurales que emergen con más fuerza que antes. Muy evidentes en varios países de América Latina, pero que también están presentes en Uruguay. Son ejemplos de esas desigualdades, la alta informalidad en el trabajo que hay en los departamentos del norte y noreste del país (próxima al 45 \%, mientras en Montevideo es del $17 \%)^{2}$ o la reducción en las últimas décadas del número de pequeños productores y producción familiar (sobre todo de leche y ganadería), con la consecuente concentración de la tierra. Con respecto a esto último, según Arbeletche (2020), un 2,5\% de las explotaciones disponen del $34 \%$ de la tierra en Uruguay

1 Aumento del bienestar que es reflejado en diversos indicadores, como la significativa caída de la pobreza o el aumento del acceso a servicios básicos y protección social, por ejemplo (Presidencia de la República, 2017). 
(Concentración que podría ser mayor, si las grandes empresas reportan desde sus ejercicios productivos individuales y no como una única empresa).

Estudiar el movimiento cooperativo agrario es de interés por su potencial de contribución a la mejora de la calidad de vida en los territorios rurales, situando a los actores locales como protagonistas privilegiados del proceso productivo. Más en general, el cooperativismo agrario puede ser una forma de dotar a los territorios de modelos de desarrollo endógeno.

Después de exponer los objetivos y la motivación del trabajo, lo que sigue del documento se organiza de la siguiente forma. A continuación, se desarrolla un marco conceptual que argumenta los puntos de encuentro entre el desarrollo territorial y el cooperativismo. Luego se presenta la metodología utilizada. En la sección de resultados, se muestra la evidencia recabada y se describe la relación entre las cooperativas agrarias y el desarrollo territorial en Uruguay. Por último, se concluye para el caso uruguayo y se reflexiona, en general, sobre el aporte que el cooperativismo agrario puede realizar para promover el desarrollo territorial.

\section{Marco conceptual: cooperativas agrarias y desarrollo territorial}

\section{Desarrollo territorial y cooperativismo}

En primer lugar, vamos a explicitar la visión sobre el desarrollo territorial que es asumida en este artículo. Reproducimos, para tal fin, la definición elaborada por el Núcleo Interdisciplinario de Estudios de Desarrollo Territorial de la Universidad de la República:

El desarrollo territorial es un proceso orientado —y por lo tanto un proyecto- con el objetivo de mejorar la calidad de vida de la comunidad que habita un territorio específico. Mejorar la calidad de vida, como actividad liberadora, incluye la cobertura de necesidades básicas, el aumento de capacidades endógenas y la creación de valor en el territorio. Este proceso involucra transformaciones estructurales en las dimensiones política, económica, social, cultural y ambiental, pero estas transformaciones, sus características y grado, dependen del territorio específico a considerar. Esto supone un profundo reconocimiento de las diferencias y de los múltiples modos de desarrollo y, por lo tanto, un abordaje ético. Un proceso 
de desarrollo territorial es sustentable, equitativo e instituyente en todas las dimensiones mencionadas. Involucra, a su vez, el control democrático de los recursos y su gestión (recursos en sentido amplio, considerando recursos naturales, económicos, financieros, humanos, culturales e institucionales). Considera al conflicto como parte de cualquier proceso humanoy logra gestionarlo. Incorpora innovación, pero recuperando tradiciones. (Magri, Abrahan y Ogues, 2014, p. 27).

A la luz de esta definición, el cooperativismo parece tener potencial para aportar, en la teoría y en la práctica, a impulsar las transformaciones económicas, sociales, culturales, políticas y ambientales, necesarias para lograr construir un proyecto de cambio que apunte a la mejora de la calidad de vida de las poblaciones de los diferentes territorios. En efecto, los principios cooperativos, que son las directrices mediante las cuales las cooperativas ponen en práctica sus valores, están estrechamente vinculados con los contenidos de la definición interdisciplinaria planteada para el desarrollo territorial ${ }^{3}$.

Las coincidencias en la importancia de los valores y en la vocación de cambio que comparten el desarrollo territorial y el cooperativismo, pueden explicarse porque ambos son enfoques que nacen orientados a la acción y tienen como objetivo la transformación de la sociedad. En ese sentido, buscan llevar a la práctica determinados principios y valores. Son esos principios y valores los que dan sentido y sustento a las acciones sociales y a las políticas de desarrollo local (Pike, Rodríguez-Pose y Tomaney, 2011). Por lo tanto, las visiones de desarrollo desde el territorio no deberían dejar de lado principios y valores fundamentales como la democracia, el internacionalismo, los derechos humanos y la justicia (Pike, Rodríguez-Pose y Tomaney, 2007). Esto permite elevar la mira hacia un plano superior, ya que el territorio deja de ser concebido como un espacio menor reducido solamente a atender particularidades. Por el contrario, el territorio aparece como un escenario mayor donde entran en juego las diferentes macrovisiones del desarrollo (Arocena y Marsiglia, 2017).

Una categoría importante como nexo entre el concepto de desarrollo territorial y las cooperativas es la noción de desarrollo endógeno. El desarrollo endógeno considera a las redes y vínculos entre los agentes económicos del territorio como

3 Los principios cooperativos son: i) asociación voluntaria y abierta; ii) control democrático de los miembros; iii) participación económica de los socios (contribución equitativa y control democrático); iv) autonomía e independencia; v) educación, formación e información; vi) cooperación entre cooperativas; vii) sentimiento de comunidad (en la cual subyace una idea de proyecto socioterritorial). (Alianza Cooperativa Internacional, en línea). 
factores estratégicos para mejorar los procesos de producción e innovación (Méndez, 2006). En estos procesos resultan muy relevantes las instituciones del territorio (reglas de juego) que tienen estrecha relación con las características socioeconómicas y culturales de las comunidades locales (Vázquez-Barquero y Rodríguez-Cohard, 2016; Rodríguez-Pose, 2013). Bajo esta visión, el territorio debe tener capacidad de decisión política sobre los asuntos de su interés (con incidencia efectiva), capacidad de ser protagonista del proceso productivo local (para poder apropiarse del excedente generado), así como ser promotor de impulsos propios de cambio (innovación), todo lo cual se combina e interrelaciona en forma sinérgica a partir de la componente sociocultural de cada territorio (Boisier, 1993). Por lo tanto, el desarrollo no resulta de la importación de modelos exitosos en otros lugares, sino que se genera sobre la base de la movilización activa de las capacidades locales (Alburquerque, 2015).

La importancia que se le otorga a las capacidades locales, tanto desde la economía solidaria como en las teorías del desarrollo endógeno, explica por qué en estos enfoques se considera que los procesos de desarrollo son más exitosos cuando se producen "desde abajo hacia arriba" (Vázquez-Barquero, 2018). A diferencia de la mirada funcional en la economía tradicional, la visión del desarrollo económico territorial no considera solamente a la tecnología y los recursos disponibles (como el trabajo, el capital o los recursos naturales), sino que asume que dichos procesos están afectados y condicionados por la organización económica, social e institucional del territorio (Rodríguez-Miranda, 2014). Por lo tanto, la cooperación será muy relevante para contribuir a la generación de capacidades territoriales para la interacción, la gestión del conflicto y la visión y acción estratégica. En este sentido, ambos enfoques buscan saldar diferencias entre la búsqueda de rentabilidad y la distribución de beneficios, con la solidaridad como pilar fundamental, a partir de lo cual se logran consensos entre las políticas públicas, las empresas y los movimientos sociales (Vázquez Barquero, 2018).

Como establecen Segura y Céspedes (2017), las cooperativas cumplen diferentes roles sociales en sus comunidades y tienen impacto en términos de desarrollo. En particular, las cooperativas promueven el desarrollo integral territorial mediante la generación de redes y vínculos en las comunidades y economías locales (Bretos, DíazFoncea, Marcuello y Marcuello 2018; Bauer, Guzmán y Santos, 2012). En comparación con otros actores, por ejemplo las empresas tradicionales, las cooperativas tienden a producir mayores beneficios sociales y económicos para las comunidades donde se localizan, incluyendo efectos positivos sobre la reducción de la desigualdad (Salazar, 2017). Por lo tanto, las cooperativas, junto con otros actores y organizaciones, tienen mucho que aportar a la construcción colectiva de desarrollo territorial. 
8 Contribución de las cooperativas agrarias al desarrollo territorial en Uruguay

\section{Desarrollo territorial y cooperativismo agrario}

En el desarrollo de las zonas rurales, a la luz de los actuales procesos económicos de transnacionalización, la convergencia entre desarrollo territorial y cooperativismo asume una importancia crítica. En efecto, la globalización, extendiendo el modelo de agronegocio transnacional, basado en la industria agroquímica global, la tecnificación y las economías de escala, ha logrado aumentar los volúmenes de producción a niveles nunca vistos. Sin embargo, como efectos colaterales han surgido importantes problemas ambientales y sociales que traen consigo consecuencias muy nocivas, sobre todo para los pequeños productores y las comunidades rurales (Brugger y Dávila, 2013).

Según Méndez (2006), los espacios rurales enfrentan el reto de reconstruir sus economías y dinamizar sus sociedades para responder a las nuevas condiciones que imperan en el capitalismo global. En este contexto, el mundo rural encuentra problemas serios como la exclusión social y la pobreza, el envejecimiento de la población y la distribución desigual de la tierra (García-García, 2017). En el abordaje de estos desafíos, las cooperativas pueden ofrecer mejores respuestas que las empresas productivas tradicionales, ya que presentan una mayor flexibilidad organizativa, estabilidad operativa, capacidad distributiva y para cooperar con otros actores (García-García, 2017). En esa misma línea, Bretos y Mancuello (2017) plantean que las cooperativas están en capacidad de crear mejores condiciones para el desarrollo de los territorios, ya que pueden compensar los efectos negativos que tiene la globalización, sobre todo reduciendo la inestabilidad económica y sociolaboral, fortaleciendo la soberanía democrática de las comunidades locales. En general, las cooperativas agrarias son un espacio plausible, a pesar del predominio del modelo productivo centrado en los agronegocios, para que los territorios puedan ser organizados desde la economía social (Lopez-Castro, 2020).

De acuerdo con Schejtman y Berdegué (2004), el desarrollo territorial rural es un proceso de transformación productiva e institucional de un espacio rural determinado, cuyo fin es reducir la pobreza y contribuir al bienestar socioeconómico. Esta definición tiene dos pilares estrechamente relacionados. El primero, se refiere a la articulación competitiva y sustentable de la economía local con mercados dinámicos. El segundo, destaca la relevancia de las reformas institucionales para modificar las reglas de juego en el medio rural. Reglas (formales e informales) que reproducen la exclusión de los pobres de los beneficios de la transformación productiva. Este problema es más evidente en el medio rural respecto al medio urbano, porque el capital social es más débil y las asimetrías de poder son más fuertes, al tiempo que los 
procesos de transnacionalización tienen impactos profundos en las sociedades y economías locales (Schejtman y Berdegué, 2004).

Con el fin de lograr las transformaciones necesarias para el desarrollo territorial rural, las cooperativas tienen el potencial de asumir un rol clave en la construcción de coaliciones sociales que den soporte a proyectos de desarrollo viables y estables. Las coaliciones sociales se refieren a un conjunto de diferentes actores que realizan acciones convergentes en torno a una dinámica territorial de desarrollo (Fernández y Hernández, 2012). Como plantean Berdegué, et al. (2012), las coaliciones sociales no representan grupos de interés o corporativos, sino que se basan en la diversidad de actores con objetivos convergentes. Esto no significa que exista un proyecto único y consensuado, pero sí permite lograr expresar y defender ciertos objetivos y metas compartidas. Para estos autores, la coalición debe sostenerse más allá de la convergencia puntual de intereses en el corto plazo, tiene que contar con variados recursos, capitales y activos, aportados por los diferentes actores que la integran, así como mostrar capacidad de acción articulada efectiva (para no quedar solo en el discurso). En esa construcción colectiva son muy importantes los aportes de las iniciativas colaborativas y las organizaciones locales.

En efecto, en Martí, Marqués, Pastorini, De Torres, Isola y Cánepa (2010) se identifican contribuciones del cooperativismo agrario en varias dimensiones del desarroIlo. En lo económico, mencionan el aporte para crear valor en el territorio y fortalecer su tejido productivo. En lo social, el cooperativismo contribuye a la permanencia de la población en el medio rural, a través de la creación de empleo y mejores condiciones de vida. Mejoras que van más allá de lo laboral y que abarcan, por ejemplo, aspectos como el acceso a educación, salud, transporte, electricidad, entre otros servicios. En cuanto a los procesos políticos institucionales, las cooperativas agrarias pueden contribuir con los procesos de diseño de políticas públicas y su implementación.

En esa misma línea, varios trabajos muestran que las cooperativas y las organizaciones de la economía social han sido protagonistas del crecimiento productivo, de los cambios estructurales y de la mejora del bienestar de la población en los territorios rurales (Rodríguez, Mozas y Bernal, 2002; Brugger y Dávila, 2013; GómezLópez y Ortiz-Pérez, 2014; Sili, Sanguinetti y Meiller, 2014; García-García, 2017). En definitiva, dentro de un enfoque de desarrollo territorial rural, las cooperativas agrarias pueden jugar un papel importante, al promover coaliciones y alianzas locales para el desarrollo y generar capacidades productivas endógenas. Además, pueden apoyar la conexión competitiva del territorio con mercados externos, pero sin sufrir el proceso de concentración que genera el capital transnacional, y defendiendo una estrategia productiva viable en la que los actores locales son protagonistas. 


\section{Metodología}

La metodología empleada consiste en un análisis descriptivo y exploratorio (Hernández, Fernández y Baptista, 2014) con perspectiva histórica, a partir de revisión bibliográfica y documental, información secundaria disponible y entrevistas a informantes clave. Las entrevistas se realizaron para completar información faltante, comprender mejor el fenómeno e identificar fuentes de información, por lo que la selección de los entrevistados respondió a un muestreo intencional para estos fines (Piovani, 2007).

El trabajo presenta, a través del análisis, hallazgos e interpretaciones de los procesos descriptos que documenten y evidencien una relación positiva entre cooperativismo agrario y desarrollo territorial, en los términos que postula el marco teórico desarrollado. Para tal fin, se analiza la evolución general del movimiento cooperativo uruguayo, el marco normativo y la relación con las políticas públicas, así como la descripción de los casos y las experiencias más representativas para el cooperativismo agrario.

De esta forma se busca comprender la contribución de las cooperativas agrarias para: i) viabilizar producciones familiares y de pequeños y medianos productores, evitando que sean absorbidos por las lógicas de concentración del capital y favoreciendo sistemas productivos locales basados en la cooperación; ii) construir redes y capital social en el territorio; iii) dar participación al territorio en ámbitos de gobernanza y toma de decisiones, con incidencia en otras dimensiones, además de la productiva; iv) interactuar con las políticas públicas favoreciendo el rol del Estado como promotor del desarrollo en los territorios rurales; v) generar capacidades endógenas en los territorios, productivas, tecnológicas y sociales.

\section{Resultados}

\section{Historia y evolución del cooperativismo en Uruguay}

Los orígenes del cooperativismo en Uruguay datan de la segunda mitad del siglo XIX. Sus inicios se relacionan con el aporte de los inmigrantes europeos y núcleos católicos que promovieron la creación de organizaciones solidarias como gremios, sindicatos, sociedades de socorros mutuos y cooperativas. Todas estas organizaciones tenían como finalidad: mejorar las condiciones de vida de los trabajadores. En algunos casos se constituyeron como cooperativas de trabajo y en otros como cooperativas de consumo. 
A principios del siglo $x x$, el desarrollo del cooperativismo encuentra un contexto favorable propiciado por las políticas impulsadas durante las presidencias de José Batlle y Ordoñez (que darían lugar a la corriente política conocida como batllismo). Estas políticas marcaron una temprana presencia del Estado en Uruguay como promotor del desarrollo productivo, buscando la modernización del país y el desarrollo de las cadenas productivas agroindustriales (Martínez-Galarraga, Rodríguez y Willebald, 2020).

Las primeras cooperativas de trabajo surgieron a partir de la organización de trabajadores en algunos rubros y oficios. Por su parte, las primeras cooperativas de consumo surgen con la organización de los trabajadores en grandes empresas industriales como la fábrica Liebig's en Fray Bentos (1903) y la Sociedad Cooperativa de Consumo "La Unión", creada por los obreros textiles de Juan Lacaze en 1909 (Terra, 2015 [1986]). La modalidad de cooperativas de ahorro y crédito, en tanto, tiene sus antecedentes en las cajas populares. Inicialmente fueron promovidas por el Segundo Congreso de los Círculos Católicos de Obreros y tenían por objetivo la democratización del ahorro y descentralización del crédito (Brena, 1980). Tuvieron una rápida difusión en el interior del país: entre 1907 y 1914 se crearon seis cajas fuera de la capital (Concari, 2016).

El origen de las cooperativas y otras organizaciones asociativas de productores en el medio rural obedeció a un triple impulso. Por una parte, la promoción de sociedades de fomento rural por la empresa inglesa del Ferrocarril Central. En segundo lugar, la creación de los llamados "sindicatos rurales", que agrupaban a los productores a partir del impulso del batllismo. Finalmente, como consecuencia del fuerte enfrentamiento entre la Iglesia y el Estado a comienzos del siglo xx, la Iglesia Católica promovió la creación de sindicatos agrícolas cristianos. Estas distintas vertientes confluyeron en el origen de muchas de las cooperativas agrarias que continúan en actividad hasta hoy (Caetano y Martí, 2019).

Al examinar el proceso histórico del cooperativismo en Uruguay, uno de sus principales estudiosos, el arquitecto Juan Pablo Terra (2015 [1986]), señala algunas regularidades que permiten comprender el fenómeno. En primer lugar, destaca la importancia del marco legal y señala que luego de cada renovación de la legislación el cooperativismo experimentó un nuevo impulso. En segundo lugar, Terra (2015 [1986]) advierte que el crecimiento del sistema como un todo, pero también la creación de cada cooperativa, han respondido en general al accionar de un motor externo al sector. Es decir, las cooperativas han sido promovidas desde el Estado, por empresas públicas, organizaciones sociales, organizaciones religiosas o por empresas capitalistas. En tercer lugar, Terra (2015 [1986]) señala la necesidad de una fuente de 
financiamiento adecuada al volumen y modalidad de las cooperativas. A esto suma una cuarta regularidad, que atañe a la dificultad para captar capital que presenta el sistema cooperativo. Por último, en relación con el rol del Estado, Terra (2015 [1986]) señala que las transformaciones en el movimiento cooperativo han estado muy vinculadas a las formas en las que la política pública se ha propuesto canalizar recursos y procesos a través del cooperativismo.

Sin embargo, a pesar de la importancia del Estado, Terra (2015 [1986]) reconoce que el movimiento cooperativo uruguayo estuvo, desde sus orígenes, fuertemente vinculado con los movimientos sociales. Al respecto, como señala Martí (2018), el movimiento cooperativo siempre mantuvo su independencia. Otro aspecto para destacar del caso uruguayo es la temprana presencia e importante desarrollo de las cooperativas en el interior del país, particularmente del cooperativismo agrario.

Respecto a la evolución del marco normativo, varios autores coinciden en señalar que hasta la aprobación de la Ley 18.407 General de Cooperativas en 2008, la legislación cooperativa se caracterizaba por ser espasmódica y fragmentaria (Reyes y Gutiérrez, 2009), tampoco existía una institucionalidad propia de promoción del desarrollo del cooperativismo (Martí, 2011).

En efecto, el desarrollo de la legislación cooperativa es relativamente reciente en Uruguay. La primera ley que abordó explícitamente el tema cooperativo fue la Ley 9526 de 1935, por la cual se creó la Cooperativa Nacional de Productores de Leche (Conaprole) con la finalidad de organizar la comercialización, industrialización y distribución de la leche en Montevideo (Martí, 2013). La aprobación de la ley respondió a la intención de poner freno al estatismo batllista pero asumiendo la necesidad política de una respuesta estatal al problema lechero. De esta forma se creó una cooperativa con presencia estatal, destinada a un grupo de productores que se beneficiaban de una concesión pública, pero a través de una organización privada cooperativa (Martí, 2018).

No fue sino hasta 1941 que se aprobó la Ley 10.008 que dio un marco normativo efectivo a las cooperativas agropecuarias. En la fundamentación del proyecto de ley se argumentaba que la situación del sector agropecuario no podía quedar librada a la iniciativa privada, e incluso que el fomento del cooperativismo era la única solución para la situación en que se encontraba el productor. Para los partidarios de la ley, la cooperativa era una institución privada que emplearía el capital con mayor eficiencia, evitaría los intermediarios y rentabilizaría la producción. La ley preveía que las cooperativas se beneficiaran de ciertos apoyos estatales y, por tanto, les exigía la neutralidad en temas políticos y religiosos; en tanto el Estado se reservaba la posibilidad de 
intervenir en su contralor o disolución. Esto afectó a los "sindicatos cristianos" que vieron limitado su desarrollo y cuestionada su identidad confesional (Martí, 2018).

En 1946 se aprobó la ley 10.761 de Sociedades Cooperativas que, en gran medida, permaneció vigente hasta la aprobación de la Ley General de Cooperativas de 2008. La ley 10.761 y el decreto reglamentario del 5 de marzo de 1948 constituyeron, durante mucho tiempo, el principal marco regulatorio de las cooperativas de consumo y de producción o trabajo asociado, así como de todas aquellas que no fueran las agrarias (Reyes y Gutiérrez, 2009). La ley identificaba a las cooperativas como sociedades de naturaleza comercial y las clasificaba como de producción o de consumo, atendiendo al criterio de distribución de los excedentes (Reyes y Gutiérrez, 2005).

Posteriormente, la legislación abordaría distintas modalidades que, a partir de la Ley 10.761, funcionaban como cooperativas de consumo, particularmente en las ramas de ahorro, crédito y vivienda, dando origen a la caracterización de la legislación como fragmentaria. Los cambios en el marco normativo dieron lugar a una legislación por modalidades de consumo, de ahorro y crédito, de vivienda, de producción y agropecuarias, lo que caracterizó la situación del cooperativismo uruguayo a lo largo del siglo $x X$.

Durante la última dictadura (1973-1985), en el marco de la promoción de las exportaciones no tradicionales, el gobierno promovió la organización de los productores agropecuarios. Se aprobaron tres normas que actualizaron el marco jurídico de las cooperativas agrarias: el Decreto-Ley 14.330 de sociedades de fomento rural de 1974, el Decreto-Ley 14.827 de cooperativas agroindustriales de 1978 y, finalmente, el Decreto-Ley 15.645 de cooperativas agrarias. El cambio legislativo propuesto por el Decreto-Ley 14.330 tuvo su origen en las limitaciones comerciales que tenían las sociedades de fomento rural (en adelante SFR), que eran asociaciones civiles impedidas para realizar operaciones comerciales (Terra, 2015 [1986]). A través de esta norma se autoriza a las SFR a "distribuir entre sus socios toda clase de insumos agropecuarios y recibir, acopiar, clasificar, conservar, envasar y elaborar los productos de las explotaciones de los mismos" (Art. $1^{\circ}$ ).

Estrechamente relacionadas con las cooperativas agrarias se encuentran las cooperativas agroindustriales. Estas fueron reguladas por el Decreto-Ley No 14.827 de Cooperativas Agroindustriales de 1978, reglamentado en 1981 a través del Decreto 415/981. El proyecto se propuso superar los obstáculos de las cooperativas agrarias para industrializar su producción y fomentar la creación de cooperativas agroindustriales como personas jurídicas que "Tendrán por objeto principal la industrialización de los productos agropecuarios provenientes de los asociados. A tales efectos podrán 
realizar toda operación concerniente a su producción, transformación y comercialización en todos sus aspectos incluyendo la exportación" (Art. 2²).

La trilogía de normativas de la última dictadura (1973-1985) para las asociaciones de productores rurales se completa en el Decreto-Ley 15.645 de cooperativas agrarias de 1984. Esta norma contiene disposiciones avanzadas con respecto a la legislación anterior, al reconocer por primera vez la especificidad del fenómeno cooperativo. Además de la introducción del concepto de acto cooperativo, establece una innovación en el marco jurídico como la ampliación del objeto de las cooperativas. También les confiere una serie de posibilidades y oportunidades como administrar créditos de distinta fuente, establecer una responsabilidad de tipo suplementada, exigir exclusividad de operaciones de los socios con la cooperativa, remunerar a los directivos, asociar a persona jurídicas o sociedades civiles y reajustar las partes sociales (De Armas Brescia, 2003).

Algunas disposiciones de la ley de cooperativas agrarias de 1984 generaron una situación que debió ser abordada por el gobierno, luego de recuperar la democracia en 1985. En primer lugar, fue necesaria su reglamentación mediante el Decreto $\mathrm{N}^{\circ}$ 556/985. Además, en el transcurso de 1985, fue necesario aprobar la Ley 15.744 y la 15.794, por medio de cuales se ampliaba el plazo fijado por el Decreto-Ley 15.645 para actualizar el Estatuto. Luego de aprobadas estas normas complementarias, las cooperativas agrarias contaron con herramientas legales más actualizadas que el resto de las cooperativas.

A partir de 1985, la legislación continuó (con algunas excepciones) ocupándose de las distintas modalidades por separado, persistiendo en la visión parcial y fragmentaria de la legislación cooperativa. Ante esto, durante casi 30 años, el movimiento cooperativo trabajó con firmeza en la actualización de la legislación cooperativa llegando incluso a presentar tres proyectos de ley. Con la llegada del Frente Amplio al gobierno nacional en 2005 se concreta finalmente la ley marco del sistema cooperativo (Guerra y Reyes, 2019). El Frente Amplio incluyó al proyecto de ley cooperativo entre sus prioridades. Se constituyó una Comisión Especial de diputados que trabajó con entusiasmo y recibió frecuentemente a los representantes del movimiento cooperativo. Finalmente, el proyecto fue aprobado por unanimidad en el Parlamento y el Poder Ejecutivo promulgó la Ley 18.407 General de Cooperativas, el 24 de octubre de 2008. La norma aprobada transforma y consolida una dispersa legislación en la materia. Tiene como objetivo regular la constitución, organización y funcionamiento de las cooperativas y del sector cooperativo. Las declara de interés general y las define como "instrumentos eficaces para contribuir al desarrollo económico y social, al fortalecimiento de la democracia y a una más justa distribución de la riqueza" (Ley 
$\mathrm{N}^{\circ} 18.407$ de 2008). Además, el Estado se compromete a garantizar y promover su constitución, libre desarrollo y fortalecimiento.

Estos cambios legislativos representan un salto cualitativo en la situación nacional y también la institucionalización de la promoción del cooperativismo (Martí, 2011). Para asegurar esta promoción, en el Artículo 186 de la Ley se crea el Instituto Nacional del Cooperativismo (INACOOP). El INACOOP tiene como finalidad proponer, asesorar y ejecutar la política nacional destinada a promover el cooperativismo y las cooperativas. Por otro lado, la ley modifica la responsabilidad del contralor de las cooperativas, pasando del Ministerio de Ganadería Agricultura y Pesca (MGAP) a la Auditoría Interna de la Nación. Adicionalmente, se crean las cooperativas mixtas, como forma de brindar una mayor flexibilidad organizacional y estableciendo incentivos para actualizar el estatuto.

Desde la aprobación de la Ley General de Cooperativas del año 2008 y la creación del INACOOP en 2009, aumentó considerablemente el número de cooperativas. Según datos del INACOOP, el número de cooperativas se incrementó de 1117 a 3653 entre 2008 y 2018. Esto implica que en 10 años se multiplicó por 3,3 el número de cooperativas (tabla 1). También crecieron las cooperativas agrarias durante ese período, multiplicando su presencia por 1,5.

Tabla 1. Cooperativas por modalidad, 2008 y 2018

\begin{tabular}{lcc}
\hline \multicolumn{1}{c}{ Modalidad } & $\mathbf{2 0 0 8}$ & $\mathbf{2 0 1 8}$ \\
\hline Agrarias & 82 & 125 \\
\hline Ahorro y crédito & 67 & 92 \\
\hline Artistas y oficios conexos & - & 5 \\
\hline Consumo & 33 & 45 \\
\hline Seguros & 2 & 2 \\
\hline Sociales & 95 & 326 \\
\hline Trabajo & 257 & 881 \\
\hline Vivienda & 581 & 2.177 \\
\hline Total & 1.117 & 3.653 \\
\hline
\end{tabular}

Fuente: elaboración propia con base en datos de INACOOP

La figura 1 muestrala geolocalización de las cooperativas en el mapa de Uruguay, de acuerdo con cada modalidad cooperativa. Se observa que las cooperativas de vivienda, de trabajo y las sociales están presentes en casi todos los departamentos, aunque tienen una fuerte concentración en los departamentos de Montevideo, San José y Canelones. Por su parte, las cooperativas agrarias también tienen presencia 
en todos los departamentos, aunque en su mayor parte se concentran en las zonas del sur y el litoral oeste del país. En el caso de las cooperativas de consumo, llama la atención la falta de presencia que tienen en la zona del noreste del país, mientras que las cooperativas de ahorro y crédito se encuentran bastante dispersas entre los diferentes departamentos. Las cooperativas de seguros y las cooperativas de artistas y oficios conexos se localizan en Montevideo.

(a) Agrarias

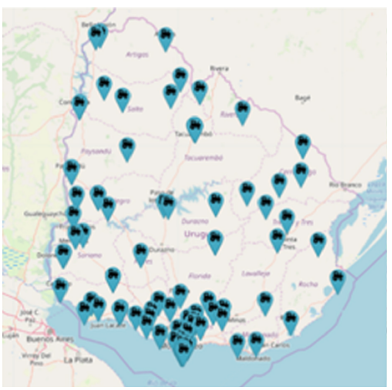

(d) Ahorro y crédito

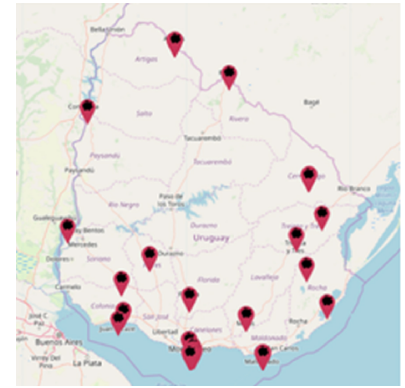

(b) Vivienda

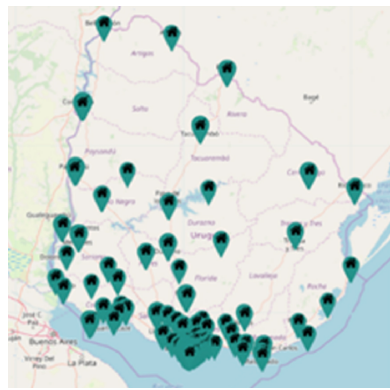

(e) Consumo

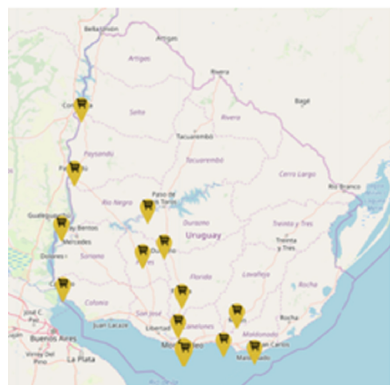

(c) Trabajo

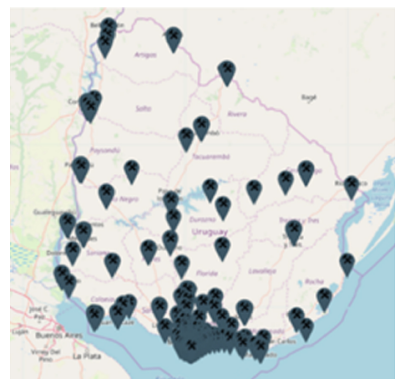

(f) Sociales

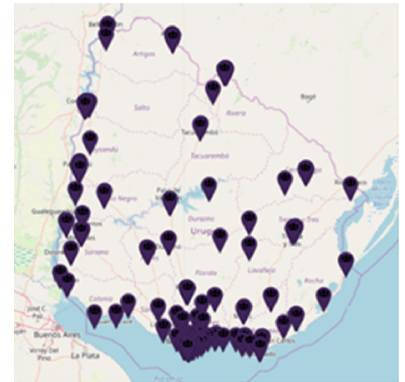

(h) Seguros

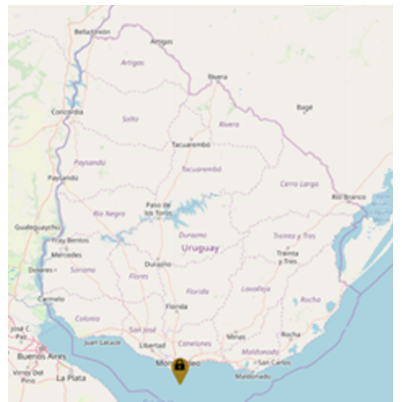

Figura 1. Localización de las cooperativas según modalidad, 2018.

Fuente: INACOOP, en línea 


\section{Las cooperativas agrarias y su contribución al desarrollo territorial}

Las primeras expresiones del cooperativismo agrario fueron las ya mencionadas SFR, creadas en las cercanías de las estaciones del ferrocarril durante la segunda década del siglo xx. Se crearon como forma de organizar a la población y mejorar su acceso a servicios, pero rápidamente evolucionaron para incorporar otras funciones y actividades; por ejemplo, intermediación y almacenamiento de insumos y productos. Incluso, con el transcurrir del tiempo, fueron asumiendo el rol de actores relevantes en sus territorios para canalizar demandas locales y aportar soluciones a diversos problemas de la población rural. Reunidas en el Congreso de Minas, el 15 de agosto de 1915, crearon la primera expresión de integración en el sector: la Comisión Nacional de Fomento Rural (CNFR), que fue reconocida posteriormente por la ley 6192 de 1918 (Terra, 2015 [1986]).

Los primeros antecedentes, en materia legislativa, hacen referencia a algunas leyes vinculadas con figuras afines al cooperativismo como, por ejemplo, las leyes $\mathrm{N}^{\circ}$ 3948 y 3949 de las Cajas de Crédito Rural de 1912. Estas leyes previeron la creación de los ya mencionados "sindicatos rurales" que agrupaban productores. La ley 3949 establecía que las cajas podían "adquirir la categoría de sindicatos rurales" y tomar a su cargo "el estudio y defensa de los intereses rurales". Estos sindicatos agrícolas dependían de la cooperativa de crédito que a su vez estaba bajo el control y la fiscalización del Banco de la República Oriental del Uruguay (banco público de fomento).

Como producto del fuerte enfrentamiento entre la Iglesia y el Estado en la época, en la "Primera Semana Social del Uruguay", organizada por los Círculos Católicos de Obreros, el presbítero Fernando Damiani realizó una exposición llamando a los católicos a promover sindicatos agrícolas cristianos (Brena, 1980). El primero sería el de Santa Lucía, fundado en 1912 con 25 socios. Con el impulso del propio Damiani nacieron también en otras localidades del interior del país. La promoción de sindicatos agrícolas fue continuada por el sacerdote Horacio Meriggi, quien fundó en 1923 el de Paysandú.

Otro de los orígenes de las cooperativas agrarias fueron las organizaciones de productores lecheros. A fines de la década de 1920, grupos de productores lecheros y médicos higienistas constituyeron en Montevideo la Cooperativa de Lecherías S.A. (Cole), con el objetivo de superar el poder de los intermediarios y valorizar su producción (Martí, 2020). En el interior del país se destaca la fundación de la Cooperativa de Lechería de Melo (Coleme), surgida por iniciativa del ingeniero agrónomo Julio de Soto, director de la Escuela Agraria de Melo, a comienzos de la década de 1930 
(Gil Villamil, 2003). Posteriormente, Cole fue absorbida por Conaprole al momento de su fundación y Coleme, desde hace pocos años atrás, produce en el marco de un acuerdo con Conaprole.

Como ya se señaló, en 1935 se crea la Cooperativa Nacional de Productores de Leche (Conaprole), que surge a partir de una ley que se hace con el objetivo de organizar el mercado interno de los lácteos, acceder a mercados de exportación, así como diversificar la producción y mejorar la calidad de los productos (Bertullo, Castro, Isola y Silveira, 2003). La intervención estatal para la creación de Conaprole dio respuesta al Ilamado problema de la leche que conjugaba dos aspectos. Por un lado, la mala calidad de la leche consumida y las condiciones sanitarias produjo enfermedades y mortalidad infantil en Montevideo, a principios del siglo xx. Por otra parte, el problema de los productores lecheros que se encontraban en manos de los intermediarios que pagaban poco y mal la leche recibida, además de que la industria y sus altos costos hacían casi inviable la actividad lechera.

Es interesante notar cómo el carácter de cooperativa de productores lecheros de Conaprole determinó la primacía de lo agrario sobre lo industrial y lo financiero. Las plantas procesadoras de leche instaladas anteriormente concebían a la leche como un insumo para la agroindustria, en tanto Conaprole vio al proceso industrial como una prolongación de la producción agraria. Esto tuvo consecuencias positivas en la lógica del precio y en la incorporación de tecnología. Mientras el industrial hace fluctuar el precio de acuerdo con la oferta y la demanda, a los productores (así como al Estado) les interesa la estabilidad del precio para asegurarse una ganancia durante todos los meses del año. Por lo tanto, la creación de Conaprole permitió una priorización del desarrollo sostenido de las cuencas lecheras y una visión en la que los actores del territorio (los productores) toman las decisiones económicas relevantes.

La presencia de Conaprole ha permitido el desarrollo de una importante industria láctea nacional que tiene un desempeño exportador muy relevante. Conaprole concentra el 71 \% de la remisión de leche a planta (dato de 2017), representando un poco más del $70 \%$ de las exportaciones totales del sector (INALE y Asociación Nacional de Productores de Leche, 2018). Esta cooperativa representó, por sí sola, el $7 \%$ de las exportaciones totales de bienes del país en 2018, llegando a casi 500 millones de dólares, lo que la convierte en la principal empresa exportadora a nivel nacional (Cámara de Industrias del Uruguay -CIU, 2018). La cooperativa juega un rol fundamental para lograr competitividad en los mercados internacionales, por ejemplo, promoviendo la innovación y adaptación tecnológica de los productores lecheros. Además de mejorar los procesos productivos y la calidad del producto, también apoya el desarrollo de las capacidades de gerencia en los productores lecheros. 
Tal como señalaba Terra (2015 [1986]), los impactos de la renovación del marco normativo son evidentes. Es así como, a partir de 1941 con la aprobación de la Ley 10.008 de cooperativas agrarias, se intensificó la creación de cooperativas. En 1955, en ocasión del Primer Congreso Nacional de Cooperativas Agropecuarias, se contabilizaron 40 cooperativas, mientras que en 1962 ya eran 109 (Terra, 2015 [1986]). La mayoría de las cooperativas brindaban servicios a los productores, desde la provisión de insumos hasta la comercialización de los productos. La actividad de estos establecimientos era muy diversa: ganadería, lechería, cereales, caña de azúcar, horticultura, fruticultura, etcétera.

El crecimiento de las cooperativas agrarias también produjo la creación de varias agrupaciones de cooperativas, aunque muchas hayan desaparecido. Por ejemplo, la Federación Nacional de Cooperativas Agropecuarias (FENACOA) creada en 1956 que, sin embargo, al poco tiempo entró en crisis para cerrar en el año 1965. Luego, en 1960 se crea la Cooperativa Agraria Limitada de Fomento Rural (CALFORU) que fuera impulsada por la CNFR buscando facilitar la compra y venta de insumos y productos para los pequeños productores rurales. Esta cooperativa también ha desaparecido.

Una innovación en la integración cooperativa, en el ámbito rural, se dio por las Ilamadas "centrales". Su concepción partió de la idea de separar funciones, depositando las funciones gremiales en las federaciones y las de comercialización o industrialización en las centrales. Entre las centrales se pueden mencionar la Central Uruguaya (1967), la Central Cooperativa de Carnes (1978), la Central Cooperativa de Granos (1984), la Cooperativa Nacional Forestal (1990) y la Central Apícola Cooperativa (1992). Si bien la mayoría dejaron de existir, destacan dos experiencias que no solo persistieron en el tiempo sino que se constituyeron en referentes de la actividad productiva a nivel nacional. Nos referimos a la Central Lanera Uruguaya y a la Cooperativa Agraria Nacional (COPAGRAN), esta última heredera de la anterior Central Cooperativa de Granos.

La Central Lanera Uruguaya se compone actualmente de 43 cooperativas y Sociedades de Fomento Rural y exporta prácticamente el 100 \% de la lana remitida por sus socios. Además, es también una experiencia de integración hacia la fase industrial. En efecto, en 1971 comienza con un negocio en el que enviaba lana a peinar a façon para luego exportar en tops. Posteriormente, en 1988, realiza una inversión para tener parte de una peinaduría, adquirida en su totalidad por la central en el año 2001. Esta planta industrial se localiza en el departamento de Florida y tiene como producto final la elaboración de tops para exportación.

Por su parte, la Central Cooperativa de Granos se transformó, en los noventa, en un Consorcio de Cooperativas Agrícolas y, en 2005, se constituyó en la Cooperativa 
Agraria Nacional (COPAGRAN). COPAGRAN es actualmente un actor de primer orden en el sector agrícola. Su existencia permitió que los medianos y pequeños productores pudieran participar de una parte de los beneficios del boom agrícola exportador de comienzos de los 2000. Sin COPAGRAN seguramente muchos productores hubieran sido excluidos en la lógica del agronegocio dirigido por grandes capitales (exigente en grandes escalas de producción y alta tecnificación).

Como se puede apreciar, en un país de clara vocación agroexportadora y de importante inserción en los mercados internacionales de estos productos, el movimiento cooperativo agrario ha permitido conjugar ese crecimiento productivo y la inserción global, en forma compatible con el desarrollo de sistemas productivos locales en torno a cadenas de valor regionales y nacionales. Esto ha sido fundamental para que los pequeños productores y la producción familiar pudieran participar del comercio internacional, pero mediado por las cooperativas y las centrales cooperativas, como forma de resguardo del riesgo de ser absorbidos y desplazados por los intereses del gran capital transnacional.

Otro hito significativo es la creación, en 1984, de las Cooperativas Agrarias Federadas (CAF) (CAF, 2014). La CAF es una institución transversal a los diferentes rubros agrarios que reúne cooperativas agrarias de primer y segundo grado. Actualmente, la CAF se compone de más de 20 entidades socias (cooperativas de primer y segundo grado, junto con SFR), lo que representa aproximadamente a unos 13.000 productores rurales (pequeños y medianos, mayormente familiares) de diversos rubros, generando unos 4000 puestos de trabajo.

En la figura 2 se puede observar que los departamentos del país con mayor concentración de cooperativas asociadas a la CAF son los que se ubican en el sur y el litoral oeste del país. En los casos de Canelones, Colonia, Flores, San José y Soriano, las cooperativas asociadas tienen un perfil dirigido mayoritariamente al rubro lechero. Por otra parte, en Colonia, Río Negro, Soriano y Paysandú se concentran las cooperativas dedicadas a cultivos. También se destacan, en menor medida, algunas cooperativas de ganaderos. Es interesante notar que las zonas del país que muestran mayor concentración de cooperativas asociadas a la CAF coinciden con las regiones que históricamente presentan mejores infraestructuras, mayor densidad de población y redes más consolidadas de ciudades intermedias, acceso a puertos de exportación y, en general, mejores indicadores de desarrollo económico (Galarraga, Rodríguez, y Willebald, 2020). 


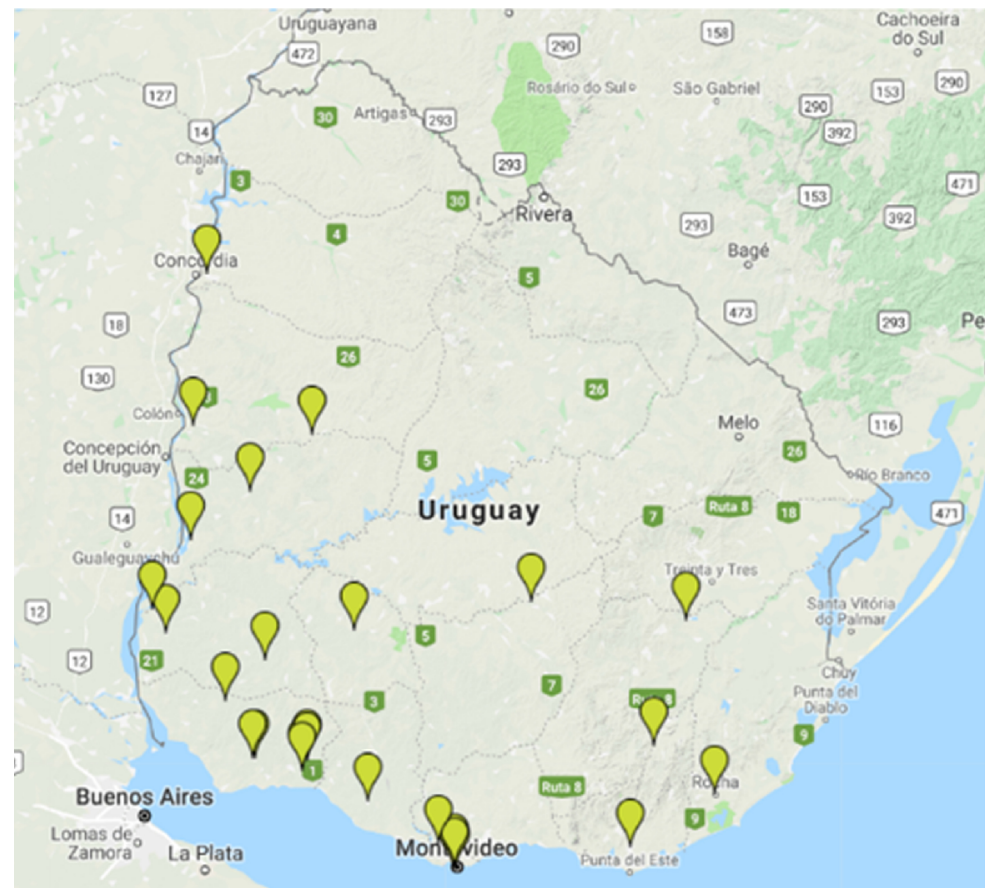

Figura 2. Localización de las Cooperativas Agrarias Federadas (CAF). Fuente: CAF, en línea.

A partir de información proporcionada por la CAF, se destacan diversos servicios que las cooperativas agrarias brindan a sus socios y a otros productores del territorio donde se localizan. Entre los servicios más relevantes se pueden mencionar el asesoramiento técnico, la venta de insumos, los servicios de comercialización y acopio, las actividades de capacitación y formación y el acceso al financiamiento (en general, mediante el crédito de la propia cooperativa en la compra de insumos). Por otro lado, como se ha señalado, en algunos rubros las cooperativas han desarrollado procesos de transformación de la materia prima, mejorando las condiciones de acceso a la fase industrial.

También, mediante información suministrada por las CAF, se puede afirmar la importancia de las cooperativas socias en la producción nacional. Así, por ejemplo, la industria Lanera Piedra Alta, propiedad de Central Lanera, procesa un $15 \%$ de la lana del país y exporta a más de 20 mercados. En tanto que, en la producción de granos, las cooperativas nucleadas en la CAF representan aproximadamente un $15 \%$ de la superficie cultivada de soja y un $25 \%$ del total de los productores del rubro, con algo más del 50 \% de la capacidad total de almacenaje de granos. En torno a la producción láctea, ya se mencionó que Conaprole concentra aproximadamente el 70 \% del procesamiento y de las exportaciones del sector. 
Podemos afirmar que la forma de organización cooperativa de la producción tiene una gran significación en la economía agrícola de Uruguay. Además, esto se produce con buenos resultados de competitividad para las producciones locales en el acceso a los mercados globales. Más allá de la necesaria competitividad internacional, el aporte diferencial respecto al modelo liderado por grandes capitales transnacionales, desde un punto de vista de desarrollo local, comprueba que el negocio se mantiene (aunque sea en parte) en las manos de los productores locales. Esto hace posible que se desarrollen estrategias propias de innovación y comercialización, que se facilite una mayor apropiación local del excedente económico y, por ende, mayor capacidad de decisión local sobre la reinversión del capital. Esto no asegura, pero sí favorece un mayor potencial de impacto sobre el resto de la economía del territorio.

En efecto, las cooperativas son actores fundamentales para construir capacidades locales con competitividad internacional. En la producción de granos, destacan la alianza entre CAF y el Instituto de Investigaciones Agropecuarias (INIA) para innovar en variedades de semillas de trigo y soja (creando grupos de trabajo como Grupo Soja y Grupo Trigo). En la ganadería se apoya la búsqueda de nichos de mercado que valoren los atributos especiales de la carne producida con el uso de invernada con pasturas naturales. En las actividades frutícola y vitivinícola, las cooperativas brindan apoyo para la conservación de la fruta de los productores y en el manejo del control de plagas.

A su vez, hay que destacar que la CAF ha desarrollado alianzas con empresas no cooperativas en clave de cadena de valor. Son ejemplos de esto los acuerdos con la industria cervecera, con escritorios rurales y frigoríficos y con las empresas comercializadoras y exportadoras de granos. Estas estrategias buscan bajar el riesgo vinculado a la inversión productiva, ya que reducen la incertidumbre ofreciendo un horizonte más previsible respecto a la colocación de la producción.

En suma, queda en evidencia la importancia que tiene el cooperativismo agrario en el medio rural en Uruguay y su contribución a mejorar las posibilidades de desarrollo territorial. En ese sentido, la CAF y la CNFR manifiestan en forma explícita, como objetivos de su actividad, la mejora de la calidad de vida en las comunidades en las que se localizan las cooperativas.

\section{Algunos desafíos actuales para las cooperativas agrarias y el medio rural}

Uno de los desafíos más relevantes a nivel mundial es el intenso proceso de transformaciones técnico-productivas que afecta al sector agrícola (Brugger y Dávila, 2013; 
García-García, 2017). El paradigma definido como "agronegocio", mediante el uso intensivo de tecnología (en buena parte innovaciones en diversas TIC) y gran capacidad de capital, genera transformaciones profundas en la organización de la producción hacia la extranjerización y concentración de la tierra (CAF, 2019; Arbeletche, 2020).

Martínez, Delgado y Pedrosa (2019) analizan las lógicas territoriales de las cadenas agroexportadoras para el caso de Uruguay desde 2003. Ese estudio deja en evidencia que se han producido profundas transformaciones en el agro uruguayo con fuertes impactos territoriales, con el surgimiento de dos nuevas cadenas de valor vinculadas al agronegocio: la sojera y la forestal-celulósica. Estas nuevas cadenas productivas han alcanzado en valor a las exportaciones de carne, que ha sido históricamente el rubro más importante del país. Este modelo, a la vez que ha contribuido a aumentar el PIB y las exportaciones del país, ha sido fuertemente concentrador de la tierra, expulsando a pequeños productores y afectando incluso a los sectores de la ganadería y lechería, tanto por la competencia por el recurso tierra como por la incursión en la propia ganadería de la lógica del agronegocio (Arbeletche, 2020).

Otros problemas, que son característicos del medio rural, tienen que ver con las dificultades para la renovación generacional en las cooperativas, así como con la fuerte masculinización de la titularidad de los recursos. A su vez, hay una brecha importante entre hombres y mujeres en el acceso a los órganos de decisión de las cooperativas y también en la participación en el empleo (CAF, 2019; Marqués, Pastorini y De Torres, 2008).

Finalmente, los aspectos ambientales suponen desafíos cada vez mayores. El uso intensivo de agroquímicos en la producción ha conducido a la necesidad de crear nuevas regulaciones sobre seguridad y calidad de los productos a nivel internacional. Esto es un gran desafío para lograr la adaptación de la pequeña y mediana producción a las nuevas reglamentaciones. Específicamente, y con una visión estratégica, es necesario apoyar la transición hacia modos de producción sostenibles. En este sentido, se debe mejorar el control para evitar malas prácticas que afectan a los predios vecinos y su producción (por ejemplo, la muerte de colmenas o afectación de producción orgánica por mala práctica de fumigación en predios vecinos), así como la afectación del medioambiente y a la salud humana (por ejemplo, afectación de zonas pobladas por fumigación aérea de grandes extensiones o contaminación de las aguas por aplicación de productos químicos en zonas demasiado próximas a los cursos de agua). A su vez, el impacto del cambio climático sobre la producción agrícola es un desafío muy importante; allí es necesario apoyar especialmente a los pequeños productores rurales para que puedan adoptar una estrategia integral de gestión de riesgos. Para 
alcanzar estos objetivos, las cooperativas agrarias pueden ser socios estratégicos, nada despreciables, en el desarrollo de la política pública.

\section{Conclusiones}

Si bien las cooperativas agrarias tienen un foco claro en resolver problemas productivos o de comercialización para los productores, rápidamente se preocupan por el entorno y toman acciones en consecuencia. Esto se debe a su propia naturaleza, ligada a la suerte del territorio que es su espacio de vida y trabajo, siendo este un aspecto que constituye la fuerza del desarrollo local (Becattini, 2006; Alburquerque, 2015). Pero su mayor contribución al desarrollo social y al bienestar de la población del territorio está justamente en cómo se aborda la cuestión productiva.

Las cooperativas agrarias abren un espacio de acción para generar sistemas productivos locales competitivos dentro de un modo diferente de desarrollo, por oposición a un modelo que vincula, en forma asimétrica y desfavorable, al productor familiar aislado con los intereses de las cadenas globales de valor. Sin embargo, como se establece en Martí, Marqués, Pastorini, De Torres, Isola, y Cánepa (2010), las cooperativas no pueden ni deben estar por fuera de los procesos de innovación que ocurren en el marco de la globalización. La inserción competitiva en los mercados es fundamental desde la perspectiva del desarrollo territorial rural, para lo cual es necesario lograr círculos virtuosos de innovación. En este sentido, el caso uruguayo es muy relevante ya que muestra un movimiento cooperativo independiente y emprendedor, junto con un Estado que ha privilegiado muchas veces a las cooperativas como instrumentos para canalizar políticas de organización productiva en clave exportadora.

Algunas experiencias exitosas como el surgimiento de grandes cooperativas (como CANAPROLE), la integración en las cooperativas de la fase agroindustrial (como COPOGRAN) y la creación de las centrales cooperativas para la comercialización (como Central Lanera) han permitido lograr la inserción de los territorios en la economía global, sin que los sistemas productivos locales sean absorbidos y diluidos dentro de los esquemas de organización del capital transnacional. En estas experiencias, las cooperativas interactúan y cooperan con otras cooperativas, con empresas tradicionales, con la política pública y con los centros tecnológicos (ej. INIA). Se trata de un modelo que permite la generación de conocimiento y aprendizaje propio y una mayor captación del excedente económico, para ser reinvertido en el propio sistema productivo local. En consecuencia, las cooperativas agrarias realizan una importante contribución a la endogeneidad del desarrollo territorial rural. 
En la práctica, las cooperativas en Uruguay han sido constructoras de espacios rural-urbanos de redes y capital social, favoreciendo una visión de desarrollo territorial rural, donde lo urbano es soporte de lo rural, al tiempo que lo rural es fundamento de lo urbano (Rodríguez, 2010). Esto es muy relevante en un país altamente especializado en rubros exportables organizados en cadenas de valor agrícolas que se localizan en territorios rurales, pero con redes extendidas de ciudades pequeñas y medianas. En efecto, para generar desarrollo local en el interior de Uruguay se hace necesario pensar en estrategias de especialización productiva en escalas regionales supradepartamentales que se apoyen en las redes existentes de ciudades pequeñas e intermedias (Rodríguez, Galaso, Goinheix y Martínez, 2017). La mirada conjunta de las regiones productivas con los sistemas urbanos podría generar estrategias de especialización en distintas funciones de las ciudades, con el fin de desarrollar un sistema de competitividad territorial que favorezca la inserción competitiva de la pequeña producción rural (Rodríguez, 2019). Esto requiere generar masa crítica de capital humano y social, insumos necesarios para la construcción de estrategias de desarrollo que se sustenten en alianzas y coaliciones sociales de base territorial. Para tal fin, las cooperativas agrarias y las SFR pueden estar llamados a ser actores privilegiados, junto con otros actores y otros colectivos de los territorios.

En este punto hay que señalar que este documento tiene las limitaciones de ser un trabajo descriptivo y exploratorio, por lo que no se concluye en una forma inequívoca. De todas formas, se han encontrado evidencias suficientes como para sostener que hay una relación positiva entre el cooperativismo agrario y el desarrollo territorial en Uruguay. Esto permite considerar nuevas investigaciones que puedan profundizar en algunas de las experiencias o dimensiones que se han destacado a lo largo de este trabajo.

Adicionalmente, es necesario señalar que el desafío para las cooperativas de contribuir al desarrollo es grande. El factor asociativo no asegura en forma infalible el éxito. Como se ha expuesto, hay varios ejemplos de iniciativas de cooperativas y alianzas que, a pesar de tener un fuerte componente innovador, no lograron perdurar en el tiempo. En efecto, el cooperativismo agrario no solo enfrenta el desafío de las transformaciones productivas, sino que también enfrenta el reto de las transformaciones sociales y culturales. No es fácil trabajar en ese sentido, porque no se trata de un proceso lineal sino de un proceso complejo que se sustenta en la horizontalidad de las relaciones y en el convencimiento de las partes.

Por otra parte, un cooperativismo agrario competitivo en contextos cada vez más desafiantes solo puede sostenerse con mayores vínculos con el sistema institucional nacional de I+D+i. Esto es necesario para aprovechar mejor las políticas 
y recursos que se han generado durante los últimos lustros para promover la innovación en Uruguay. A su vez, un cooperativismo emprendedor y con capacidad de reinventarse requiere resolver problemas de participación democrática y de inclusión de ciertos colectivos. En particular, el cooperativismo agrario no puede darse el lujo de no aprovechar el capital humano y la fuente de renovación que representaría la incorporación plena a la actividad cooperativa de los jóvenes y las mujeres.

Asumir estas dificultades, como parte del proceso, implica abordar definitivamente el problema del desarrollo desde la perspectiva territorial y endógena. Esto supone abandonar la idea del desarrollo concebido como un resultado de grandes inversiones externas o de otros factores exógenos. Por lo tanto, implica dar un debate con trasfondo ideológico, en el cual el cooperativismo tiene mucho potencial para aportar a una visión territorial del desarrollo. Visión que, como ya señalamos, no es ajena a ciertos principios y valores rectores.

\section{Referencias}

Alburquerque, F. (2015). El enfoque del desarrollo económico territorial. Enfoque, estrategias e información para el desarrollo territorial. Los aprendizajes de ConectaDEL, pp.15-44. FOMINBID y ConectaDEL.

Alianza Cooperativa Internacional (s.f.). ¿Qué es una cooperativa? [en línea]. https://www.ica. coop/es.

Arbeletche, P. (2020). El agronegocio en Uruguay: su evolución y estrategias cambiantes en el siglo XXI. RIVAR, 7(19), 109-129.

Arocena, J. y Marsiglia, J. (2017). La escena territorial del desarrollo: Actores, relatos y políticas. Taurus.

Asociación Nacional de Productores de Leche. (s.f.). Asociación Nacional de Productores de Leche [en línea]. http://www.anpl.org.uy/

Bauer, C. M., Guzmán, C. y Santos, F. J. (2012). Social capital as a distinctive feature of Social Economy firms. International Entrepreneurship and Management Journal, 8, 437-448.

Berdegué, J., Bebbington, A., Escobal, J., Favareto, A., Fernández, I., Ospina, P. Munk, H., Aguirre, F., Chiriboga, M., Gómez, I., Gómez, L., Modrego, F., Paulson, S., Ramírez, E., Schejtman, A. y Trivelli, C. (2012). Territorios en Movimiento. Dinámicas Territoriales Rurales en América Latina. Documento de Trabajo Nº 110. Programa Dinámicas Territoriales Rurales. Rimisp. 
Bertullo, J., Castro, D., Isola, G. y Silveira, M. (2003). El cooperativismo en Uruguay. Red Universitaria de las Américas en Estudios Cooperativos y Asociativismo.

Boisier, S. (1993). Desarrollo regional endógeno en Chile. ¿Utopía o necesidad?. Ambiente y Desarrollo, IX(2), CIPMA.

Brena, T. (1980). El pensamiento y la acción de los católicos en el Uruguay. Montevideo: Club Católico de Montevideo y Unión Económica del Uruguay.

Bretos, I. y Marcuello, C. (2017). Revisiting globalization challenges and opportunities in the development of cooperatives. Annals of Public and Cooperative Economics, 88(1), 47-73.

Bretos, I., Díaz-Foncea, M., Marcuello, C. y Marcuello, C. (2018). Cooperativas, capital social y emprendimiento: Una perspectiva teórica. REVESCO. Revista de Estudios Cooperativos, 128, 76 98. DOI: 10.5209/REVE.59775

Brugger, J. y Dávila, M. (2013). Las cooperativas agrícolas ecológicas como motor del desarrollo sustentable. Un estudio neo-institucionalista de las cooperativas coreanas Hansalim e Icoop en Corea del Sur. Revista Académica PROCOAS - AUGM. I(5).

Caetano, G. y Martí, J. P. (2019). Lo que nos une. Cudecoop: 30 años de cooperativismo. Cudecoop, Inacoop, Inefop, MEC y MTSS.

CAF. (2014). 30 años produciendo futuro. 1948-2014. Cooperativas Agrarias Federadas.

CAF. (2019). Propuestas al próximo gobierno. Cooperativas Agrarias Federadas.

CAF. (s.f.). Cooperativas Agrarias Federadas [en línea]. www.caf.org.uy

Cámara de Industrias del Uruguay (CIU). (2019). Informe Anual de Exportaciones de Bienes del Uruguay 2018. https://n9.cl/crxng

CEPAL. (2017). Panorama del desarrollo territorial en América Latina y el Caribe, 2017. CEPAL.

CEPAL. (2019). Enfoque territorial y análisis dinámico de la ruralidad: alcances y límites para el diseño de políticas de desarrollo rural innovadoras en América Latina y el Caribe. CEPAL.

Concari, G. (2016). Las Cajas Populares en la primera mitad del siglo XX en Uruguay. Cuadernos de RSO. Publicación interdisciplinaria sobre responsabilidad social de las organizaciones, 4(1), 21-36. 
De Armas Brescia, S. (2003). Proceso de asociativismo en organizaciones de productores del Departamento de Soriano. [Tesis para obtener al título de Ingeniero Agrónomo], Universidad de la República, Montevideo.

Fernández, M. I. y Hernández, R. (edits.), (2012). Coaliciones sociales y desarrollo territorial. Publicaciones IEP.

García-García, F. (2017). Debate sobre la inclusión del cooperativismo dentro de las políticas de la nueva ruralidad en América Latina. Panorama Económico, 25(3), 357-380.

Gil, G. (2003). Historia de COLEME. [Trabajo realizado a pedido de la administración de COLEME]. COLEME, Cerro Largo.

Gómez-López, J. D. y Ortiz-Pérez, S. (2014). Propuesta para la territorialización de las cooperativas agrarias y los emprendimientos solidarios del Baixo Tocantins en el estado de Pará, Brasil. Cooperativismo \& Desarrollo, 104(22), 21-33. DOI: http://dx.doi.org/10.16925/co.v22i104.972

Guerra, P.y Reyes, S. (2019). La construcción legislativa uruguaya en economía socialy solidaria en el marco de los gobiernos progresistas del Frente Amplio. Cooperativismo \& Desarrollo, 27(114), 1-18. DOI: https://doi.org/10.16925/2382-4220.2019.01.05

Gutierrez, D. y Reyes, S (2009). “Uruguay” en Reunión Especializada de Cooperativas del MERCOSUR (RECM): "Régimen legal de las cooperativas en los países del MERCOSUR", ( $3^{\mathrm{a}}$ ed.). RECM-Serie Jurídica.

Hernández, R., Fernández, C. y Baptista Lucio, P. (2014). Metodología de la investigación (6ª ed.). McGraw-Hill.

INACOOP. (s. f.) Instituto Nacional del Cooperativismo Fondo para el Desarrollo [en línea]. www. inacoop.org.uy

INALE. (s.f.). Instituto Nacional de la Leche [en línea]. http://www.inale.org

IMPO. (2008). Ley Nº 18.407: Ley de cooperativas, regulación, constitución, organización y financiamiento (2008) IMPO. https://www.impo.com.uy/bases/leyes/18407-2008

Lopez-Castro, N. (2020). Estrategias del cooperativismo agrario frente a las transformaciones sociales y productivas recientes. Una exploración en el sudoeste bonaerense (Argentina). Cooperativismo \& Desarrollo, 27(2),1-32. DOI: https://doi.org/10.16925/2382-4220.2020.02.03 
Magri, A., Abrahan, M. y Ogues, L. (2014). Nuevos desafíos y respuestas de los actores sobre el desarrollo local. La Paloma y Nueva Palmira frente a propuestas de inversión. Universidad de la República, Fondo de Cultura Universitaria.

Marqués, J., Pastorini, M. y De Torres, F. (2008). Los procesos de integración regional y de globalización en el cooperativismo agrario del Uruguay. Revista de Estudios Cooperativos, 13(1), Unidad de Estudios Cooperativos, UdelaR.

Martí, J. P. (2011). Legislación y fomento del cooperativismo en Uruguay. Esfuerzos espasmódicos fragmentarios y reactivos. Revista de Estudios Cooperativos, 16(2), 10-26. Unidad de Estudios Cooperativos, UdelaR.

Martí, J. P. (2013). La Cooperativa Nacional de Productores de Leche. Su creación analizada desde las políticas públicas. América Latina en la Historia Económica, 20, 90-113.

Martí, J. P. (2018). Estado, mercado y cooperativas. Los orígenes de la legislación cooperativa en Uruguay a través del debate parlamentario (1935-1946). En P. Guerra (Ed.), Aportes desde la Universidad de la República al campo temático de la Economía Socialy Solidaria (pp. 163-192). Red Temática en Economía Social y Solidaria -UDELAR.

Martí, J. P. (2020). Mercado, políticas públicas y cooperativas de productores en la lechería uruguaya a comienzos del siglo XX. Cooperativismo \& Desarrollo, 28(116), 1-33. Recuperado: https://revistas.ucc.edu.co/index.php/co/article/view/3124

Martí, J. P., Marqués, J., Pastorini, M., De Torres, F., Isola, G. y Cánepa, G. (2010). Los procesos de integración regional y de globalización en el cooperativismo agrario del Uruguay. Servicio Central de Extensión y Actividades en el Medio, Unidad de Estudios Cooperativos. Universidad de la República.

Martínez, E., Delgado, M. y Pedrosa, R. (eds.), (2019). Lógicas territoriales del Uruguay agroexportador. Facultad de Arquitectura, Diseño y Urbanismo de la Universidad de la República y Ministerio de Vivienda, Ordenamiento Territorial y Medioambiente de Uruguay.

Martínez-Galarraga, J., Rodríguez, A. y Willebald, H. (2020). Patterns of regional income distribution in Uruguay (1872-2012): a story of agglomeration, natural resources and public policies. [en prensa]. Badia-Miró, Tirado-Fabregat y Willebald (ed.). Time and Space: Latin American Regional Development in Historical Perspective. Palgrave MacMillan.

Méndez, R. (2006). La construcción de redes locales y los procesos de innovación como estrategias de desarrollo rural. Problemas del Desarrollo, 37 (147), 218-240. 
Pike, A., Rodríguez-Pose, A. y Tomaney, J. (2007). What Kind of Local and Regional Development and for Whom? Regional Studies, 41(9),1253-1269.

Pike, A., Rodríguez-Pose, A. y Tomaney, J. (2011). Local and regional development. Reflections and futures. Pike, A., Rodríguez-Pose, A. y Tomaney, J. (edits.). Handbook of Local and Regional Development. Routledge.

Piovani, J. I. (2007). La entrevista en profundidad. Marradi, A., Archenti, N. y Piovani, J. (edits.). Metodología de las ciencias sociales (pp. 215-225). Emecé.

Presidencia de la República (2017). Objetivos de Desarrollo Sostenible. Informe Nacional Voluntario Uruguay 2017. https://ods.gub.uy/images/OPP_informe_completo_digitalUV.pdf

Reyes, S. y Gutiérrez, D. (2005). Situación de la legislación cooperativa uruguaya. Régimen legal de las cooperativas en los países del Mercosur ( $2^{\mathrm{a}}$ ed.). Intercoop.

Reyes, S. y Gutiérrez, D. (2009). Uruguay. Régimen legal de las cooperativas en los países del Mercosur ( $3^{\mathrm{a}}$ ed.). Reunión Especializada de Cooperativas del Mercosur (RECM).

Rodríguez, J., Mozas, A., Bernal, E. (2002). Desarrollo local por cooperativas: Diversificación productiva en el ámbito rural Andaluz. El caso de Bedmar. Revesco. Revista de Estudios Cooperativos, 76, 173-189.

Rodríguez, A. (2010). Desarrollo económico en el noreste de Uruguay: articulación rural-urbana y organización productiva. Serie Documentos de Trabajo, DT 03/2010, Instituto de Economía, FCEA, UDELAR.

Rodríguez, A. (2014). Desarrollo económico y disparidades territoriales en Uruguay. Cuaderno Nº 03, Serie El Futuro en Foco, Programa de las Naciones Unidas para el Desarrollo.

Rodríguez, A. (2019). Dinámicas productivas regionales y sistema urbano nacional. Martínez, E., Delgado, M. y Pedrosa, R. (comp.). Lógicas territoriales del Uruguay agroexportador. Facultad de Arquitectura, Diseño y Urbanismo de la Universidad de la República y Ministerio de Vivienda, Ordenamiento Territorial y Medioambiente de Uruguay, Montevideo.

Rodríguez, A., Galaso, P., Goinheix, S. y Martínez, C. (2017). Especializaciones productivas y desarroIlo económico regional en Uruguay. Serie Documentos de Trabajo, DT 07/2017. Instituto de Economía, FCEA, UDELAR.

Rodríguez-Pose, A. (2013). Do Institutions Matter for Regional Development? Regional Studies, 47(7), 1034-1047. 
Salazar, S. (2017). The Creation and Distribution of Benefits in Cooperatives: Some Comparative Findings. Review of International Co-operation, 104, 135-147.

Schejtman, A. y Berdegué, J. (2004). Desarrollo territorial rural. Rimisp (Centro Latinoamericano para el Desarrollo Rural).

Segura, A., Céspedes, J. (2017). Contributions from Cooperatives to Development: Methodological Input for Awareness of the Cooperative Phenomenon. Review of International Co-operation, 104, 148-161.

Sili, M., Sanguinetti, J. y Meiller, A. (2014). El cooperativismo agrario y su contribución al desarroIlo rural. La experiencia de la Unión Agrícola de Avellaneda, Argentina. CIRIEC-España, 82, 155-177.

Terra, J.P. (2015 [1986]). Proceso y significado del cooperativismo uruguayo. (2 ${ }^{\mathrm{a}}$ ed.). Instituto Humanista Cristiano Juan Pablo Terra.

Vázquez-Barquero, A. (2018). Reflexiones teóricas sobre la relación entre desarrollo endógeno y economía social. Revista Iberoamericana de Economía Social y Solidaria, 1,11-22.

Vázquez-Barquero, A., y Rodríguez-Cohard, J. C. (2016). Endogenous development and institutions: Challenges for local development initiatives. Environment and Planning. C, Government \& Policy, 34(6), 1135-1153. https://doi.org/ 10.1177/0263774X15624924

\section{Otras fuentes consultadas:}

Entrevistas realizadas a los directivos de Cooperativas Agrarias Federadas (CAF), provenientes de diferentes cooperativas de todo el país.

Entrevistas realizadas al Gerente y equipo técnico de Cooperativas Agrarias Federadas (CAF).

Información solicitada al Instituto Nacional del Cooperativismo (INACOOP). 